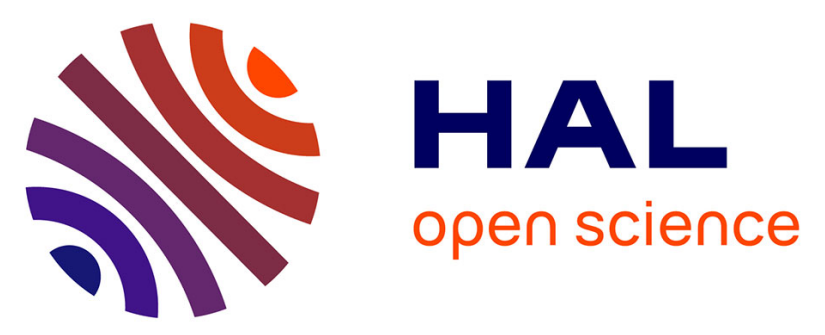

\title{
AGE-RELATED CHANGES IN NEUROMUSCULAR FUNCTION AND PERFORMANCE FOLLOWING A HIGH-INTENSITY INTERMITTENT TASK IN ENDURANCE TRAINED MEN
}

François Bieuzen, Christophe Hausswirth, Jeanick Brisswalter, Julien Louis

\section{To cite this version:}

François Bieuzen, Christophe Hausswirth, Jeanick Brisswalter, Julien Louis. AGE-RELATED CHANGES IN NEUROMUSCULAR FUNCTION AND PERFORMANCE FOLLOWING A HIGHINTENSITY INTERMITTENT TASK IN ENDURANCE TRAINED MEN. Gerontology, 2010, 56 (1), pp.66-72. hal-01781794

\section{HAL Id: hal-01781794 \\ https://hal-insep.archives-ouvertes.fr/hal-01781794}

Submitted on 30 Apr 2018

HAL is a multi-disciplinary open access archive for the deposit and dissemination of scientific research documents, whether they are published or not. The documents may come from teaching and research institutions in France or abroad, or from public or private research centers.
L'archive ouverte pluridisciplinaire HAL, est destinée au dépôt et à la diffusion de documents scientifiques de niveau recherche, publiés ou non, émanant des établissements d'enseignement et de recherche français ou étrangers, des laboratoires publics ou privés. 
AgE-RELATED CHANGES IN NEUROMUSCULAR FUNCTION AND PERFORMANCE FOLLOWING A HIGH-INTENSITY INTERMITTENT TASK IN ENDURANCE TRAINED MEN.

Bieuzen François ${ }^{1,2,3}$, Hausswirth Christophe ${ }^{1}$, Louis Julien², Brisswalter Jeanick ${ }^{2}$

${ }^{1}$ Institut National du Sport et de L'Education Physique (INSEP), Laboratoire de Biomécanique et de Physiologie, 11 Avenue du Tremblay, 75012 Paris, France.

${ }^{2}$ Laboratoire Ergonomie Sportive et Performances, Handibio, EA 3162, Université du Sud Toulon-Var, Av. De I'Université, BP 132, 83957 La Garde Cedex, France.

${ }^{3}$ ESPHI, Human Performance Centre, Université du Sud Toulon-Var, Av. De I'Université, BP 132, 83957 La Garde Cedex, France

Short title: Regular endurance training and neuromuscular function with aging

\section{Corresponding author:}

Dr Bieuzen François

${ }^{1}$ Institut National du Sport et de L'Education Physique (INSEP), Laboratoire de Biomécanique et de Physiologie, 11 Avenue du Tremblay, 75012 Paris, France.

$\triangle$ Email: francois.bieuzen@insep.fr

Tel: +33(0)1 41744165

Fax: +33 (0)14174 4535 
Background: A greater attention has been focused on the need to design strategies to increase functional capacities in older populations. This has raised several questions regarding the ability of regular endurance training to preserve functional capacity with age.

Objective: The purpose of this study was to examine the age-associated changes in neuromuscular function in endurance trained men before and after a high-intensity, intermittent fatigue task.

Method: 26 healthy endurance trained male subjects: 16 old (59-79 yrs) and 10 young (20-34 yrs) men performed a high-intensity, intermittent fatigue exercise corresponding to 10 sets of 10 repetitions on a horizontal leg press at $70 \%$ of the individual one repetition maximum. Maximal voluntary contractions (MVC) and evoked contractions of the knee extensors muscles were performed before and after the exercise.

Results: Decreases in MVC (old: -9.7\% and young: -14.3\%) and electromyographic activity were not different between groups. Peak twitch torque was reduced only for the old men and no changes in voluntary activation and $\mathrm{M}$-wave properties were recorded in either group.

Conclusion: The present study indicates in endurance trained men aged 59-79 years that muscle functional capacities are maintained despite losses in strength and contractile function related to the age.

KEYWORDS: AGING - ENDURANCE TRAINING - NEUROMUSCULAR PERFORMANCE - M-WAVE - EVOKED TWITCH 


\section{INTRODUCTION}

With aging, a great number of structural and functional transformations occur leading to a decline in "optimal" physical capacity. Many of the changes in physiological functional capacity related to aging have been found to be the result of long standing sedentary lifestyle [1,2]. This reduction in physical capacity with aging is related to many factors including a reduction in physical activity as well as changes in body composition [3] and/or the development of clinical diseases. Because of the increasing number of older men and women in our society, the possibility of reducing or even preventing these age-related troubles has received increased interest. Within this framework, greater attention has been focused on the need to design strategies to increase functional capacity in older persons [4-6] but also to enhance the performance of master athletes. Indeed, studies have shown that master endurance athletes are able to maintain their performance despite structural changes in the muscle classically described with aging $[7,8]$. These observations have raised several questions on the benefit of regular endurance training on preserving functional capacity with age. During long distance events, performance depends on classical endurance qualities such as maximal aerobic capacity, efficiency of locomotion and neuromuscular performance $[9,10]$. However, the majority of studies have focused on the effects of resistance training but few available studies have investigated endurance trained populations [11-15].

The positive effect of regular physical activity on performance and well being in older adults is well known. However, the effect on neuromuscular performance appears controversial [16-27]. These conflicting results could be mainly attributed to different methodologies as well the nature and the characteristics of training rather than the fitness level of subjects.

Classically in the scientific literature, neuromuscular function is studied using a fatiguing task and assessed by the decrease in maximal force-generating capacity. This is particularly the case during long distance events where significant decrease in muscular performance is systematically described with exercise duration (e.g. [28]). More recently, many studies have investigated neuromuscular function with fatigue using electromyography and electrical stimulation techniques $[21,23,29,30]$. These non-invasive techniques use the measurements of $\mathrm{M}$-wave and twitch amplitude and duration to better characterise the origin of neuromuscular fatigue (i.e. central and/or peripheral fatigue) [31].

Within this context, the purpose of this study was to compare the maximal isometric contraction, EMG activity, voluntary activation, M-wave and twitch properties of the knee extensors muscles in two groups of endurance trained young and older men. Specifically, we investigated 1) age-associated changes in neuromuscular performance in endurance trained men; and 2) age-associated changes in neuromuscular performance following a high-intensity intermittent fatigue task in endurance trained men. 


\section{MATERIALS AND METHODS}

$\nabla$

SUBJECTS AND OVERALL DESIGN - The investigation was conducted on 16 healthy older men (Age, $66.1 \pm 5.8$ yrs [59-79 yrs]; height, $1.75 \pm 0.06 \mathrm{~m}$; body mass, $76.4 \pm 7.1 \mathrm{~kg}$ ) and on 10 young men (Age, $25.4 \pm 4.6 \mathrm{yrs}$ [20-34 yrs]; height, $1.80 \pm 0.07 \mathrm{~m}$; body mass, $75.0 \pm 8.6 \mathrm{~kg}$ ). All subjects were free from present or past neuromuscular conditions that could affect motor function. Subjects were fully informed about the protocol, and informed consent was obtained prior to all testing. This study was approved by a local research ethics committee (Saint Germain-en-Laye, France). Particular care was taken in recruiting young and older individuals with the same training level. The individuals selected for this investigation (both young and older adults) were trained in endurance activities (cycling) for at least 6 years (Cycling hours per week, Young: $11.7 \pm 4.0 \mathrm{~h}$; Older: $10.9 \pm 2.2 \mathrm{~h}$ ) and were not reticent to perform the fatiguing task.

PROCEDURES - One week after a full familiarization session, subjects performed an exercise protocol composed of 10 sets of 10 repetitions on a horizontal leg press (Technogym, Gambettola, Italy) at an intensity of $70 \%$ of the one repetition maximum (1 RM). 1RM values were obtained during the familiarisation session the week before using standard procedures [29]. The rest between sets was 90-s. The exercise consisted of a 3-s concentric contraction followed by a 3-s eccentric contraction. Each contraction started from a position of $90^{\circ}$ of knee flexion to reach to a knee flexion of $170^{\circ}$. The subjects were verbally encouraged to carry out all the sets. All subjects were able to complete the 10 sets of 10 repetitions.

Immediately before (Pre) and after (Post) the exercise, neuromuscular assessments were performed. The average time between the end of the fatiguing exercise and the post-fatigue neuromuscular assessments was $25 \mathrm{sec}$.

\section{NEUROMUSCULAR ASSESSMENTS}

Torque measurements - A force transducer was used to measure maximal isometric torque of the right knee extensors (KE) muscles generated voluntary and with electrical stimulation. Subjects were seated in an experimental chair, (Schnell Trainingsgesäte $\mathrm{GmbH}$, Peutenhausen, Germany) with a $110^{\circ}$ hip angle and a $100^{\circ}$ knee angle. Arms were folded and placed on their chest avoiding any pulling from the side-handfuls of the chair. The knee axis was aligned with the ergometer axis and the ankle was attached to the ergometer leg arm extending from the transducer. In the testing session the subjects were asked to perform maximal isometric contractions $\left(0 \mathrm{rad}^{-1} \mathrm{~s}^{-1}\right.$ ) of the KE muscles of 2-3-s duration. The best performance of the three trials was defined as MVC. The subjects were strongly encouraged and the three trials were executed with a 1-min rest period between each trial.

Electrically Evoked Contractions. - Electrical stimulation was applied to the right femoral nerve with a monopolar cathode ball electrode $(0.5-\mathrm{cm}$ diameter) pressed into the femoral triangle by the experimentalist. The anode was a $50 \mathrm{~cm}^{2}(10 \times 5 \mathrm{~cm})$ rectangular electrode (Medicompex, Ecublems, Switzerland) located in the gluteal fold opposite the cathode. The subject positioning was exactly the same as for the torque measurements. A high-voltage stimulator (model DS7, Digitimer, Hertfordshire, United Kingdom) was used to deliver a square-wave pulse of $1 \mathrm{~ms}$ duration, $400 \mathrm{~V}$ maximal voltage at an intensity ranging from 50 to 110 
$\mathrm{mA}$. The optimal intensity of stimulation was set by progressively increasing the stimulus intensity until the maximal isometric twitch torque was achieved. The same intensity was used for pre and post tests. After the optimal intensity of stimulation was found, the site of stimulation was marked and three single twitches separated by two seconds were applied at rest. The same stimulus location and intensity was used for pre and post testing. The threshold for twitch torque onset was 3SD of the mean torque calculated at rest during the $100 \mathrm{~ms}$ period prior to the delivery of the stimulus. The following parameters were obtained from the mechanical response of the evoked twitch contractions: (1) peak twitch (Pt), i.e. the highest value of twitch torque production; (2) contraction time $(\mathrm{Ct})$, i.e. the time from the origin of the mechanical response to $\mathrm{Pt}$; (3) half-relaxation time (HRt), i.e. the time to obtain half of the decline in twitch maximal torque.

During each MVC, a superimposed stimulus was applied manually once the plateau of the torque was achieved to estimate an average superimposed signal. The stimulation parameters were the same as previously described. Voluntary activation level was estimated by expressing every increment in torque electrically evoked during the maximal isometric contractions (twitch size when superimposed) as a fraction of the amplitude of the response evoked by the same stimulus in the relaxed muscle (twitch size evoked at rest). This ratio was used to estimate the extent of inactivation during a voluntary contraction. Because the potentiated evoked stimulation represents full muscle activation, the superimposed torque using the same intensity of stimulation would activate those fibres left inactivated by the voluntary contraction [32]. The activation level (AL) was then estimated according to the formula [33]: AL (\%) = [1 - (twitch size when superimposed / twitch size evoked at rest)] x 100

Electromyographic recordings. - The electromyographic activity of the vastus lateralis (VL) muscle of the right leg was monitored with surface EMG during the single twitch and MVC tasks. The subjects were prepared for placement of EMG electrodes by shaving the skin of each electrode site, cleaning it carefully with alcohol wipe and lightly abrading it to maintain a low inter-electrode resistance of $<1000 \Omega$. Pairs of $\mathrm{Ag} / \mathrm{AgCl}$ pre-gelled surface electrodes (Medicotest, type Blue Sensor, Q-00-S, Denmark) of $40 \mathrm{~mm}$ diameter with a center to center distance of $25 \mathrm{~mm}$ were placed on the VL muscle for EMG data acquisition. According to SENIAM recommendations [34], the location of the electrode was place at the distal 2/3 point on the line from the anterior spina iliaca superior to the lateral side of the patella. A ground electrode was placed on a bony site over the right anterior superior spine of the iliac crest. The electrodes were secured with chirurgical tape and cloth and kept on during the fatiguing task. EMG signals were pre-amplified (Mazet Electronique Model, Electronique du Mazet, Mazet Saint-Voy, France) close to the detection site (Common Mode Rejection Ratio, $C M R R=100 \mathrm{~dB} ; \mathrm{Z}$ input $=10 \mathrm{G} \Omega$; gain $=600$, bandwidth frequency = from $6 \mathrm{~Hz}$ to $1600 \mathrm{~Hz}$ ). Prior to acquisition, a third order, zero lag Butterworth antialiasing filter at $500 \mathrm{~Hz}$ was applied. EMG data were collected from VL muscle, digitized through an acquisition board (DT 9800-series, Data Translation, Marlboro, USA) and stored on a computer to be analyzed using custom-written add-on software (Origin $6.1^{\circ}$, OriginLab, Northampton, USA). EMG data were sampled at $10000 \mathrm{~Hz}$ and quantified by using the root mean square (RMS). Maximal RMS EMG of VL muscle was set as the maximal $500 \mathrm{~ms}$ RMS value found over the $3 \mathrm{~s}$ MVC (i.e. $500 \mathrm{~ms}$ window width, $1 \mathrm{~ms}$ overlap) with Origin $6.1^{\circ}$ software.

Peak-to-peak amplitude (PPA), peak-to-peak duration (PPD) and RMS of the M-wave $\left(\mathrm{RMS}_{\mathrm{M}}\right)$ were determined for the VL muscle during the control twitches performed before the MVC. Amplitude was defined as the sum of absolute values for maximum and minimum points of the biphasic (one positive and one negative deflection) $M$ wave. Duration was defined as the time from maximum to minimum points of the biphasic $M$ wave. The $\mathrm{RMS}_{\mathrm{M}}$ was calculated over a period from maximum to minimum points of the biphasic $\mathrm{M}$ wave. 
The maximal RMS EMG of VL muscle was normalized to the $\mathrm{RMS}_{\mathrm{M}}$ using the ratio RMS/RMS $\mathrm{R}_{\mathrm{M}}$ [28]. A reduction in the RMS without a reduction in $\mathrm{RMS}_{\mathrm{M}}$ may be interpreted as a central activation failure [35-36].

STATISTICAL ANALYSIS - All data were expressed as mean \pm standard deviation (SD). A two-way analysis of variance (group $x$ time) for repeated measures was performed to analyze the effect of groups and exercise using mechanical and EMG values as dependent variables. Tukey post-hoc test was used to determine any differences among the Pre and Post fatiguing exercise and groups. A $p$ value of $\leq 0.05$ was accepted as the level of statistical significance for all analyses.

Intrasubject variation between the three MVC trials in Pre and Post fatiguing exercise were calculated from the coefficient of variation (CV, i.e. standard deviation/mean, in \%). 


\section{RESULTS}

MVC TORQUE -Isometric MVC torque demonstrated a high reliability in Pre and Post fatigue exercise (CV, Pre: $2.08 \%$; Post: $3.07 \%$ ). A significant effect of aging was observed on MVC before exercise, with lower MVC values for old men compared with the young men (-29.4\%, $p<0.05$, Figure 1a). A significant decrease in MVC was observed after exercise $(p<0.05)$ without any difference between groups: $-9.7 \%$ for older (from $257 \pm 30$ $\mathrm{N}$ to $232 \mathrm{~N} \pm 31$ ) and $-14.3 \%$ for young (from $364 \pm 68 \mathrm{~N}$ to $312 \pm 62 \mathrm{~N}$ ) men.

CENTRAL ACTIVATION - RMS/RMS M ratio and activation level of the VL muscle did not differ between groups before exercise (Figure $1 \mathrm{~b}$ and $1 \mathrm{c}$ ). Furthermore, significantly lower values of central activation were recorded after the fatiguing exercise without any difference between age groups (RMS/RMS : Old: $0.58 \pm 0.23$ to $0.27 \pm 0.05$; Young: $0.64 \pm 0.40$ to $0.33 \pm 0.18-\mathrm{AL}(\%)$ : Old: $93.1 \pm 4.4$ to $83.0 \pm 3.8$; Young: $91.5 \pm 3.1$ to $83.1 \pm 11.7)$.

MUSCULAR TWITCH PROPERTIES - No significant effect of aging was observed on peak twitch torque before exercise but a slower $\mathrm{Ct}$ was observed for the old men compared to the young men $(p<0.05)$. The fatiguing exercise reduced Pt by $25.8 \%(p<0.05)$ in old men without any change in $\mathrm{Ct}$ or HRt when compared with preexercise values. In contrast, no significant alteration of Pt, Ct or HRt was observed in the young men after the fatiguing exercise (Table 1).

M-WAVE PROPERTIES - No significant effect of age was observed on peak-to-peak amplitude (PPA) or duration (PPD) of the M-wave for the VL muscle (Table 1). The fatiguing exercise did not change the M-wave properties (PPA and PPD) for endurance trained old or young men. 


\section{DISCUSSION}

$\nabla$

The objective of the present study was to examine the age-related changes in neuromuscular performance of the knee extensors muscles in endurance trained men before and after a high-intensity intermittent fatigue task. The main results of our study are; i) a significant difference in strength level between groups but no significant differences in the decrease in the MVC torque between the groups with fatigue; ii) no difference in the level of activation between the two groups before or after fatigue and a significant decrease in the level of activation after exercise for the two groups; iii) a significant difference in contraction time between older and young adults before exercise with a significant alteration in peak twitch torque observed only in older subjects with fatigue.

MVC TORQUE - MVC for the old men was $29 \%$ lower compared to the young men before exercise. Despite the fact that our subjects were endurance trained, this result is in accordance with the literature when muscle performance of young and older trained subjects is compared. Classically, a reduction in isometric muscle strength ( $\sim 15 \%$ to $\sim 35 \%$ ) is generally observed after the age of 60 years for the quadriceps muscles. For non endurance trained adults, this reduction is generally attributed to a loss of muscle fibres, change in the proportions of muscle fibre types [37, 38], and a reduction in muscle volume and cross-sectional area [39]. However, based on results of Coggan et al. [40] confirmed by Tarpenning et al. [14], decreases of strength capacities for masters athletes similar to our population could be explained by other factors. Indeed, these authors have shown that fibre area and fibre distribution are maintained with aging for master runners. They suggested that the decline in muscle performance may also the result of neural factors, such as muscle recruitment and/or specific tension. Therefore, in our population, the neural factors were not affected with aging suggesting that only the specific tension [41] may explain our results. However, we haven't tested the fibre area and fibre distribution of our population, so we cannot conclude on it.

Whereas old endurance trained men have lower isometric strength capacities than trained young men, we have observed a similar reduction of the relative muscle torque for old and young men after the fatiguing exercise with a decrease in strength of $-9.7 \%$ for young men and $-14.3 \%$ for old men. This could indicate that muscular function is similarly altered with aging in our trained subjects. In the literature, the comparison of the effect of fatigue on lower limb muscles between different age untrained groups provides contradictory results. Some studies suggest that old adults fatigue less than young adults [20, 21, 23] whereas other investigators have observed that older men and women fatigue more than young $[19,26]$ and some other studies have demonstrated similar fatigability in young and older adults [16-18, 22, 24, 25, 27]. For one part methodological differences especially the characteristic of the fatiguing task (e.g. high vs. low intensity, dynamic vs. static exercise, exercise duration, etc.) but also the training status of the subjects could explain this apparent inconsistency in experimental results. For example, in Lanza et al.'s study [23], young and older men were sedentary and practiced exercise less than $20 \mathrm{~min} /$ day twice a week whereas in our study all subjects were regularly trained. Therefore, our results could be explained from results on endurance trained men described in the previous section $[14,40]$ associated with a potentially neural adaptation on our population. Based on these observation and results on central activation discussed below, we can hypothesized that endurance exercise could reduce the fatiguing effect on the neuromuscular performance with aging with a lower decrease of neural factors.

CENTRAL ACTIVATION - Before the fatiguing exercise, the young and older trained men presented no difference in RMS/RMS ${ }_{M}$ ratio and activation level values. This original result could be compared with the study of Si- 
moneau et al. [42] showing that regardless of the ankle joint position, the RMS/RMS ${ }_{M}$ ratio of the triceps surae muscle was not different between old and young adults after a 1-year strength-training program. However, to the best of our knowledge, these parameters have never been investigated on endurance trained old men while neural factors were regularly suggested to explain the greater loss of strength capacities on endurance master athlete when compared to young trained men $[14,40]$. Also, in our study, no difference in central activation was observed while old men produce lower maximal strength torque than young men. This suggesting that neural factors could not be the reason of the decrease of muscular performance with aging in our specific population. Secondly, we hypothesized that chronic endurance training contributed to maintain neural factors to high level although age increases.

Similarly, we observed no difference between age groups in this ratio after the fatiguing exercise. However, both groups showed an alteration of the level of activation with fatigue. This decrease associated with decrease of muscular performance after an heavy exercise is classically described in the literature [28]. In this experiment, the two methods used for estimating central activation both attest that a central component of muscle fatigue contributes substantially to the reduction of maximal voluntary force. The reduced neural drive the motoneurons may be due to spinal and supraspinal mechanisms (for review, see Ref. 31). Fatigue can occur at levels upstream of corticospinal neurons, presumably due to neurotransmitter depletion, which could result in an impaired efficiency in generating the central command. In addition, fatigue at the spinal level might result from peripheral reflex inhibition of the $\alpha$-motoneurons by muscle-spindle afferents [31].

MUSCULAR TWITCH AND M-WAVE - Our results on the twitch properties are in agreement with previous studies since we have observed that contraction time $(\mathrm{Ct})$ and half-relaxation time (HRt) of the older compared with young subjects were greater in the unfatigued ( $\mathrm{Ct}:+34 \%$; HRt: $+43 \%)$ condition. One of the main explanations of this increase has been proposed by Jakobsson et al [43] and Lexell [37] indicating an age-related shift toward a higher percentage of type I fibres. However, this explanation was in conflict with results of Tarpenning et al. showing that Type I and Type II fibre area and distribution do not differ between age groups on endurance trained men [14]. It this case, the hypothesis of modification of the specific tension of type I and type II fibre with aging [41] could mainly explain our results; however, this hypothesis remains highly speculative and we have no data to support this. One other factor could also affect twitch contractile characteristics and could explain one part of our results. Indeed, a recent study has observed that musculotendinous stiffness decreases following strength training in elderly individuals and could be due to peripheral but also neural adaptations [44]. If we associated this original result to the fact that more compliant series elastic components in the muscles tend to decrease twitch force [45] and can also partly cause a slowing of the twitch contraction time [46], we can hypothesized that one part of our results in older men could be attributed to a reduction of the musculotendinous stiffness properties. However, we haven't tested this hypothesis, so we cannot conclude on it.

Our results showed different modifications of the twitch properties after the fatiguing exercise between groups. Indeed, older men showed a decrease in Pt after exercise suggesting an alteration of the contractile properties. This reduction is generally attributed to an alteration of the excitation-contraction coupling process that could be due to several mechanisms such as reduced $\mathrm{Ca}^{2+}$ release from the sarcoplasmic reticulum [47], change in metabolites ( $\mathrm{H}^{+}$, inorganic phosphate), and reduced capacity of cross bridges to strongly bind [48]. In contrast, Pt in the young men remained unchanged after the exercise. As recently shown at similar knee flexion angle [49], this lack of decrease could suggest that fatigue was counterbalanced by potentiation for young adults, whereas twitch potentiation of older adults was too low to counterbalance the fatigue [50, 51]. 
Before the fatiguing exercise no difference was observed between young and older men on the M-wave characteristics (i.e. PPA and PPD). This result is different from those obtained on sedentary subjects, showing an age-related reduction of $20-40 \%$ in PPA $[16,18,20]$. This results could be related to finding from the recent study by Deley et al. [11] indicating that one year of combined exercise training (endurance and resistance training) improves aerobic capacity, performance on field tests, and neuromuscular factors in healthy subjects over 70 years old. Within this framework, our results indicate that for regularly endurance trained subjects, there is no age-related alteration in neuromuscular propagation or the permeability of the sarcolemma to chloride, potassium, or sodium. Moreover, a second interesting result is that there is no potentiation of the amplitude and duration of the M-wave after the fatiguing exercise. Thus, we could suggest the benefits of regular endurance training are to preserve the excitability properties of the muscle.

In conclusion, the main result of our study showed a similar reduction of the maximal strength capacities of knee extensors muscles for endurance older and young men after a high intensity intermittent endurance exercise. Furthermore, central fatigue appeared similar in both groups but the alteration of contractile properties was greater in older adults. These results seem to indicate that in endurance trained men muscle functional capacities in men aged 59-76 years are maintained despite age-related reduction in strength and changes in contractile function. 


\section{REFERENCES}

Maharam LG, Bauman PA, Kalman D, Skolnik H, Perle SM: Masters athletes: factors affecting performance. Sports Med 1999; 28: 273-285.

2 Wright VJ, Perricelli BC: Age-related rates of decline in performance among elite senior athletes. Am J Sports Med 2008; 36: 443-450.

3 Bouchard DR, Beliaeff S, Dionne IJ, Brochu M: Fat mass but not fat-free mass is related to physical capacity in well-functioning older individuals: nutrition as a determinant of successful aging (NuAge)--the Quebec Longitudinal Study. J Gerontol A Biol Sci Med Sci 2007; 62:1382-1388.

4 Henwood TR., Taaffe DR: Short-term resistance training and the older adult: the effect of varied programmes for the enhancement of muscle strength and functional performance. Clin Physiol Funct Imaging 2006; 26: 305-313.

5 Yardley L, Bishop FL, Beyer N, Hauer K, Kempen GI. Piot-Ziegler C, Todd CJ, Cuttelod T, Horne M, Lanta K, Holt AR: Older people's views of falls-prevention interventions in six European countries. Gerontologist 2006; 46: 650-660.

6 Zieglemann JP, Lippke S: Use of selection, optimization and compensation strategies in health self regulation. J Aging Health 2007; 19: 500-518.

7 Tanaka H, Seals DR: Endurance exercise performance in Masters athletes: age-associated changes and underlying physiological mechanisms. J Physiol 2008; 586: 55-63.

8 Trappe S: Marathon runners: how do they age? Sports Med 2007; 37: 302-305.

9 Hausswirth C, Lehénaff D: Physiological demands of running during long distance runs and triathlons. Sports Med 2001; 31: 679-689.

10 Millet GY, Lepers R: Alterations of neuromuscular function after prolonged running, cycling and skiing exercises. Sports Med 2004; 34: 105-116.

11 Deley G, Kervio G, Van Hoecke J, Verges B, Grassi B, Casillas JM: Effects of a one-year exercise training program in adults over 70 years old: a study with a control group. Aging Clin Exp Res 2007; 19: 310-315.

12 Dreyer HC, Schroeder ET, Hawkins SA, Marcell TJ, Tarpenning KM, Vallejo AF, Jensky NE, Shaibi GQ, Spears S, Yamada R, Wiswell RA: Chronic exercise and skeletal muscle power in older men. Appl Physiol Nutr Metab 2006; 31: 190-195.

13 Tarpenning KM, Hawkins SA, Marcell TJ, Wiswell RA: Endurance exercise and leg strength in older women. J Aging Phys Act 2006; 14: 3-11.

14 Tarpenning KM, Hamilton-Wessler M, Wiswell RA, Hawkins SA: Endurance training delays age of decline in leg strength and muscle morphology. Medicine and science in sports and exercise 2004 ;36: 74-78.

15 Wiswell RA, Hawkins SA, Jaque SV, Hyslop D, Constantino N, Tarpenning K, Marcell T, Schroeder ET: Relationship between physiological loss, performance decrement, and age in master athletes. The journals of gerontology 2001; 56: M618-626.

16 Allman BL, Rice $\mathrm{CL}$ : Incomplete recovery of voluntary isometric force after fatigue is not affected by old age. Muscle Nerve 2002; 4: 1156-1167. 
Bemben MG, Massey BH, Bemben DA, Misner JE, Boileau RA: Isometric intermittent endurance of four muscle groups in men aged 20-74 yr. Med Sci Sports Exerc1996; 28: 145-154.

${ }^{18}$ Cupido CM, Hicks AL, Martin J: Neuromuscular fatigue during repetitive stimulation in elderly and young adults. Eur J Appl Physiol Occup Physiol 1992; 65: 567-572. Davies CT, White MJ: Contractile properties of elderly human triceps surae. Gerontology 1983; 29: 19-25. Ditor DS, Hicks AL: The effect of age and gender on the relative fatigability of the human adductor pollicis muscle. Can J Physiol Pharmacol 2000; 78: 781-790.

${ }^{21}$ Kent-Braun JA, Ng AV, Doyle JW, Towse TF: Human skeletal muscle responses vary with age and gender during fatigue due to incremental isometric exercise. J Appl Physiol 2002; 93: 1813-1823.

22 Laforest S, St-Pierre DM, Cyr J, Gayton D: Effects of age and regular exercise on muscle strength and endurance. Eur J Appl Physiol Occup Physiol 1990; 60: 104-111. Lanza IR, Russ DW, Kent-Braun JA: Age-related enhancement of fatigue resistance is evident in men during both isometric and dynamic tasks. J Appl Physiol 2004; 97: 967-975. Larsson L, Karlsson J: Isometric and dynamic endurance as a function of age and skeletal muscle characteristics. Acta Physiol Scand 1978; 104: 129-136. Lindstrom B, Lexell J, GerdleB, Downham D: Skeletal muscle fatigue and endurance in young and old men and women. J Gerontol A Biol Sci Med Sci 1997; 52: B59-66. Stackhouse SK, Stevens JE, Lee SC, Pearce KM, Snyder-Mackler L, Binder-Macleod SA: Maximum voluntary activation in nonfatigued and fatigued muscle of young and elderly individuals. Phys Ther 2001; 81: 11021109.

27 Stevens JE, Binder-Macleod S, Snyder-Mackler L: Characterization of the human quadriceps muscle in active elders. Arch Phys Med Rehabil 2001; 82: 973-978.

28 Lepers R, Maffiuletti NA, Rochette L, Brugniaux J, Millet GY: Neuromuscular fatigue during a long-duration cycling exercise. J Appl Physiol 2002; 92: 1487-1493.

${ }^{29}$ Ferri A, Narici M, Grassi, B, Pousson M: Neuromuscular recovery after a strength training session in elderly people. Eur J Appl Physiol 2006; 97: 272-279.

30 Simoneau E, Martin A, Van Hoecke J: Muscular performances at the ankle joint in young and elderly men. J Gerontol A Biol Sci Med Sci 2005; 60: 439-447.

31 Gandevia SC: Spinal and supraspinal factors in human muscle fatigue. Physiol Rev 2001; 81: 1725-1789.

32 Behm DG, St-Pierre DMM, Perez D: Muscle inactivation: assessment of interpolated twitch technique. J Appl Physiol 1996; 81: 2267-2273.

${ }^{33}$ Gandevia SC, Herbert RD, Leeper JB: Voluntary activation of human elbow flexor muscles during maximal concentric contractions. J Physiol (Lond) 1998; 512: 595-602.

34 Hermens HJ, Freriks B, Disselhorst-Klug C, Rau G: Development of recommendations for SEMG sensors and sensor placement procedures. J Electromyogr Kinesiol 2000; 10: 361-374.

35 Duchateau J, Balestra C, Carpentier A, Hainaut K: Reflex regulation during sustained and intermittent submaximal contractions in humans. J Physiol 2002; 541.3:959-967 
36 cises. Sports Med 2004; 34: 105-111

37 No, 11-16

38 Med Sci Sports 1995; 5: 129-142.

39 Hakkinen K, Keskinen KL: Muscle cross-sectional area and voluntary force production characteristics in elite strength- and endurance-trained athletes and sprinters. Eur J Appl Physiol Occup Physiol 1989; 59: 215-220.

40 Coggan AR, Spina RJ, Rogers MA, King DS, Brown M, Nemeth PM, Holloszy JO: Histochemical and enzymatic characteristics of skeletal muscle in master athletes. J Appl Physiol 1990; 68: 1896-1901 Larsson L, Li X, Frontera WR: Effects of aging on shortening velocity and myosin isoform composition in single human skeletal muscle cells. Am J Physiol 1997; 272: C638-649.

42 Simoneau E, Martin A, Van Hoecke J: Adaptations to long-term strength training of ankle joint muscles in old age. Eur J Appl Physiol 2007; 100: 507-514.

43 Jakobsson F, Borg K, Edstrom L, Grim
Muscle Nerve 1988; 11: 1211-1218.

44

Ochala J, Lambertz D, Van Hoecke J, Pousson M: Effect of strength training on musculotendinous stiffness in elderly individuals. Eur J Appl Physiol 2005; 94:126-133.

45 O'Hagan F, Tsunoda N, Sale DG, MacDougall JD: Elbow flexor evoked twitch con
trained men and women and bodybuilders. Eur J Appl Physiol 1993; 66: 240-245.

46 Rice CL, Cunningham DA, Paterson DH, Dickinson JR: Strength training alters contractile properties of the triceps brachii in men aged 65 \pm 78 years. Eur J Appl Physiol 1993; 66: 275-280.

47 Westerblad H, Lee JA, Lannergren J, Allen DG: Cellular mechanisms of fatigue in skeletal muscle. Am J Physiol 1991; 261: C195-209.

48 Metzger JM., Moss RL: pH modulation of the kinetics of a Ca2(+)-sensitive cross-bridge state transition in mammalian single skeletal muscle fibres. J Physiol 1990; 428: 751-764.

49 Place N, Maffiuletti NA, Ballay $\mathrm{Y}$, Lepers R: Twitch potentiation is greater after a fatiguing submaximal isometric contraction performed at short vs. long quadriceps muscle length. J Appl Physiol 2005; 98: 429436.

50 Baudry S, Klass M, Duchateau J: Postactivation potentiation influences differently the nonlinear summation of contractions in young and elderly adults. J Appl Physiol 2005; 98: 1243-1250.

51 Shima N, McNeil CJ, Rice CL: Mechanomyographic and electromyographic responses to stimulated and voluntary contractions in the dorsiflexors of young and old men. Muscle Nerve 2007; 35: 371-378. 
Figure 1 Mean values of the MVC of the knee extensors muscles (a), the RMS/RMS $S_{M}$ ratio (b) and the activation level (c) of the Vastus Lateralis muscle before and after the fatiguing exercise for older and young adults groups.
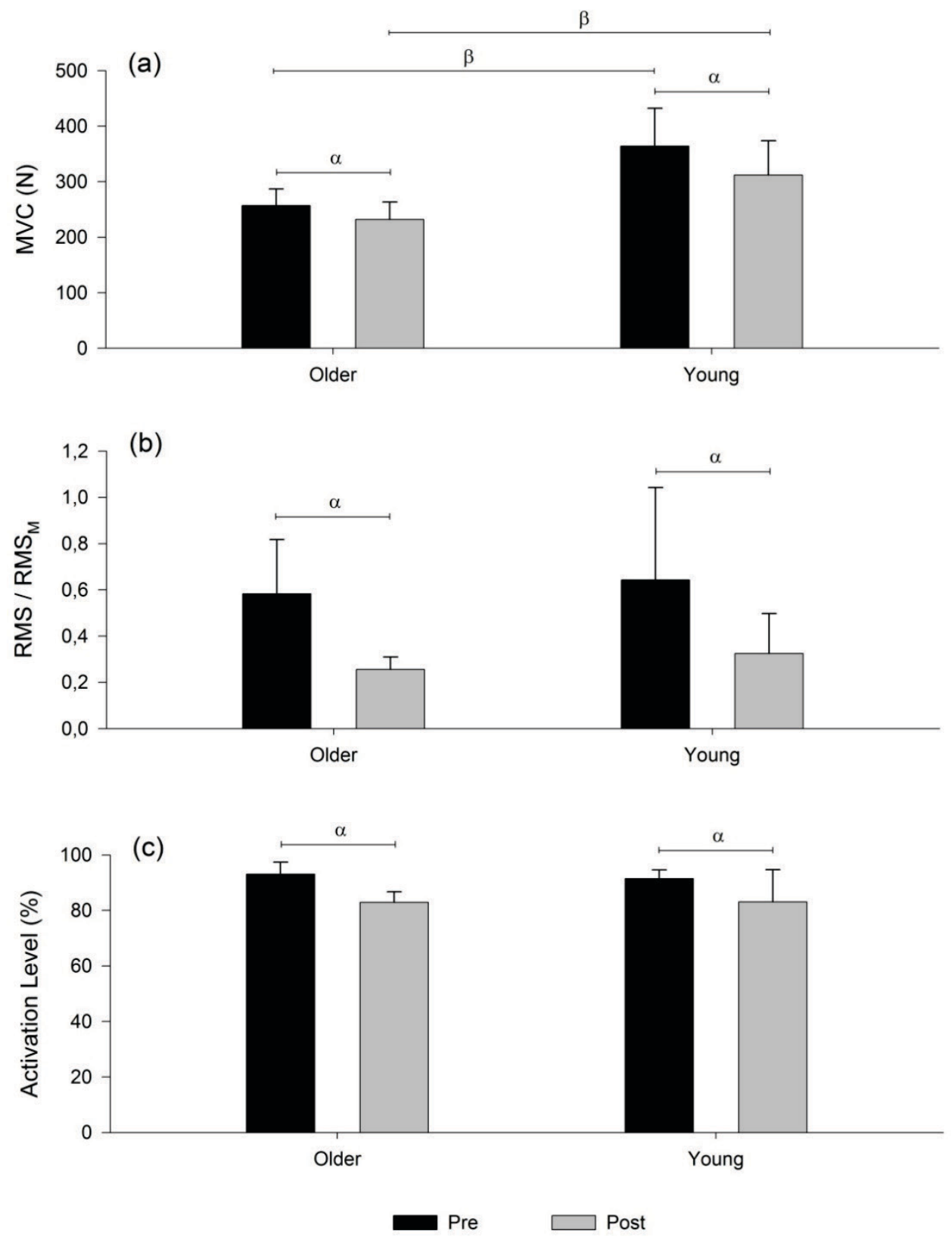

${ }^{\alpha}$, indicate significant difference between pre and post tests $(p<0.05)$.

${ }^{\beta}$, indicate significant difference between groups $(p<0.05)$ 
Table 1 Muscular twitch and vastus lateralis muscle M-wave parameters (peak twitch, i.e. Pt; contraction time, i.e. Ct; half-relaxation time, i.e. HRt; peak to peak amplitude, i.e. PPA; peak to peak duration, i.e. PPD) before and after the fatiguing exercise.

\begin{tabular}{|c|c|c|c|c|c|c|}
\hline & & \multicolumn{3}{|l|}{ Twitch } & \multicolumn{2}{|l|}{ M-wave } \\
\hline & & $\begin{array}{l}\mathrm{Pt} \\
(\mathrm{N})\end{array}$ & $\begin{array}{l}\mathrm{Ct} \\
\text { (ms) }\end{array}$ & $\begin{array}{l}\text { HRt } \\
\text { (ms) }\end{array}$ & $\begin{array}{l}\text { PPA } \\
(\mathrm{mV})\end{array}$ & $\begin{array}{l}\text { PPD } \\
\text { (ms) }\end{array}$ \\
\hline & Young & $53.8 \pm 17.3$ & $57 \pm 18$ & $68 \pm 14$ & $12.9 \pm 5.7$ & $5.8 \pm 1.8$ \\
\hline \multicolumn{7}{|c|}{ Before } \\
\hline & Older & $54.6 \pm 11.3$ & $76 \pm 18^{\beta}$ & $85 \pm 28^{\beta}$ & $18.8 \pm 8.8$ & $6.4 \pm 1.5$ \\
\hline & Young & $54.2 \pm 20.4$ & $47 \pm 21$ & $52 \pm 18$ & $12.8 \pm 6.1$ & $4.7 \pm 2.6$ \\
\hline \multicolumn{7}{|l|}{ After } \\
\hline & Older & $34.4 \pm 16.3^{\alpha, \beta}$ & $68 \pm 8^{\beta}$ & $79 \pm 36^{\beta}$ & $17.8 \pm 8.1$ & $6.2 \pm 1.7$ \\
\hline
\end{tabular}

${ }^{\alpha}$, indicate significant difference with before trial $(p<0.05)$.

${ }^{\beta}$, indicate significant difference between groups $(p<0.05)$. 